\title{
Continuous flow synthesis of Pt nanoparticles in porous carbon as durable and methanol-tolerant electrocatalysts for oxygen reduction reaction
}

\author{
Carlota Domínguez, ${ }^{[a]}$ Kevin M. Metz, ${ }^{[b]}$ Md. Khairul Hoque, ${ }^{[a]}$ Michelle P. Browne, ${ }^{[a]}$ Leticia Esteban- \\ Tejeda, ${ }^{[a]}$ Corbin K. Livingston, ${ }^{[b]}$ Suoyuan Lian, ${ }^{[a]}$ Tatiana S. Perova, ${ }^{[c]}$ Paula E. Colavita ${ }^{*}[a]$
}

\begin{abstract}
The development and commercialization of direct methanol fuel cells (DMFCs) as energy conversion devices remains a challenge despite their advantages in terms of energy density and energyconversion efficiency. The bottleneck for the development of DMFCs is mainly caused by the sluggish kinetics of the oxygen reduction reaction (ORR) at the cathode of fuel cells, and the effect of the socalled methanol-crossover in state-of-the-art $\mathrm{Pt} / \mathrm{C}$ electrocatalysts. Herein, we report for the first time an easily scalable continuous flow method based on ultraspray pyrolysis (USP), for the preparation of $\mathrm{Pt}$ nanoparticles directly embedded on highly porous carbon spheres. A study on the effect that post-synthesis treatment protocols have on the level of graphitization and catalytic properties is described. Use of USP results in a substantial reduction of the final Pt content with respect to typical $\mathrm{Pt} / \mathrm{C}$ electrocatalysts, while yielding also excellent durability and tolerance to methanol crossover in acidic conditions. Thus, making our USP method a good candidate for its use in the preparation of ORR catalysts in commercial applications.
\end{abstract}

\section{Introduction}

The development and commercialization of proton exchange membrane fuel cells (PEMFCs) as energy conversion devices is still a challenge despite the advantage of using them as a potential zero emission source of power. Direct methanol fuel cells (DMFCs) are a prime example of the issues facing the development of PEMFCs. DMFCs are attractive for their possible implementation in portable applications, due to the high energy density of methanol, and their relatively high energy-conversion efficiency. While the development of PEMFCs in general is hampered by the sluggish kinetics of the oxygen reduction reaction (ORR) that occurs at the cathode of fuel cells, ${ }^{[1]}$ DMFCs

[a] Dr. C. Domínguez, Md. K. Hoque, Dr. M P. Browne, Dr. L. EstebanTejeda, Dr. S. Lian, Dr. P. E. Colavita*

School of Chemistry, CRANN and AMBER Research Centres Trinity College Dublin

College Green, Dublin 2, Ireland

E-mail: colavitp@tcd.ie

[b] Dr. K. M. Metz, C. K. Livingston

Department of Chemistry

Albion College

611 E. Porter Street, Albion, Michigan 49224, United States

[c] Dr.T. S. Perova

Department of Electronic and Electrical Engineering

Trinity College Dublin

College Green, Dublin 2, Ireland

ITMO University,

49 Kronverskiy pr., Saint Petersburg, 197101, Russia

Supporting information for this article is given via a link at the end of the document. have the added problem of methanol crossover. Methanol crossover occurs when non-reacted methanol permeates the cathode compartment through the polymer membrane causing a decrease in the performance of the cathode catalyst. The presence of methanol at the cathode can induce a parasitic methanol oxidation reaction (MOR), which competes for the active sites needed for the ORR. Moreover, Pt/C materials used as cathodes in DMFCs can be poisoned by $\mathrm{CO}$, a byproduct in the MOR and the mixed potential generated by competing reactions reduces the overall cell potential causing an increase in water production. ${ }^{[2]}$

State-of-the-art catalysts for the ORR require the use of Pt-based materials, as these have shown the highest efficiency in terms of both activity and durability. ${ }^{[3]}$ However, the high cost and scarcity of $\mathrm{Pt}$, added to the poor long-term stability and limited tolerance to impurities of Pt-based catalysts remain important obstacles to widespread commercialization of fuel cells. ${ }^{[4]}$ As a result, many research efforts have been aimed at both reducing the $\mathrm{Pt}$ loading required to sustain the ORR, and improving the activity and the durability of the catalysts. ${ }^{[1,5]}$ For instance, Pt-based alloy NPs ${ }^{[3 c}$, ${ }^{6]}$, nanostructured Pt nanotubes or nanoshells, ${ }^{[7]}$ and Pt NPs with high-index facets ${ }^{[8]}$ have been shown to exhibit much higher activities than pure Pt-based catalysts. Moreover, during the last decades, the use of low or ultra-low loadings of Pt has been addressed in terms of activity and durability during the ORR in order to promote the development of PEMFCs. ${ }^{[9]}$ The use of Ptalloys in combination with low-cost metals has gained attention in the scientific community: a mass activity of $5.7 \mathrm{~mA} \mathrm{mg}_{\mathrm{Pt}}^{-1}$ at 0.9 $V_{R H E}$ has been demonstrated for complex structures of $\mathrm{Pt}_{3} \mathrm{Ni}-$ nanoframes. ${ }^{[3 c]}$ Multi-alloying of $\mathrm{Pt}$ with transition metals has also been reported as a promising method for improving activity in the ORR, yielding exceptional mass activity of $7 \mathrm{~mA} \mathrm{mg}_{\mathrm{Pt}}{ }^{-1}$ at $0.9 \mathrm{~V}_{\mathrm{RHE}}$ in the case of $\mathrm{Mo}-\mathrm{Pt}_{3} \mathrm{Ni} / \mathrm{C}$ catalysts. ${ }^{[6]]}$

Long-term stability of the catalysts is also of major importance for commercial implementation of electrode materials. Lack of stability of Pt-based catalysts usually arises from corrosion of the carbon support, ${ }^{[10]}$ dissolution/re-deposition of $\mathrm{Pt}$ nanoparticles/nanostructures, ${ }^{[11]}$ migration/aggregation of Pt NPs at the support surface and loss of active sites by their dissolution in the electrolyte. Many efforts have been made in improving the durability of the electrocatalysts for ORR by alloying Pt with metals ${ }^{[3 c]}$ or rare earth elements, ${ }^{[3 b]}$ and by the preparation of $\mathrm{Pt}$ monolayers, ${ }^{\left[{ }^{[c]}\right]}$ showing promising results after long-term stability tests under operation conditions. Contradictory, decreasing the loading of $\mathrm{Pt}$ to low or ultra-low loadings of $\mathrm{Pt}\left(10-70 \mu \mathrm{g}_{\mathrm{Pt}} \mathrm{cm}^{-2}\right.$ geo $)$ has been reported as not the best route for mantaining the stability of this materials. ${ }^{[9 a}$ In the case of DMFC, there is a further requirement for methanol-tolerance imposed on cathode 

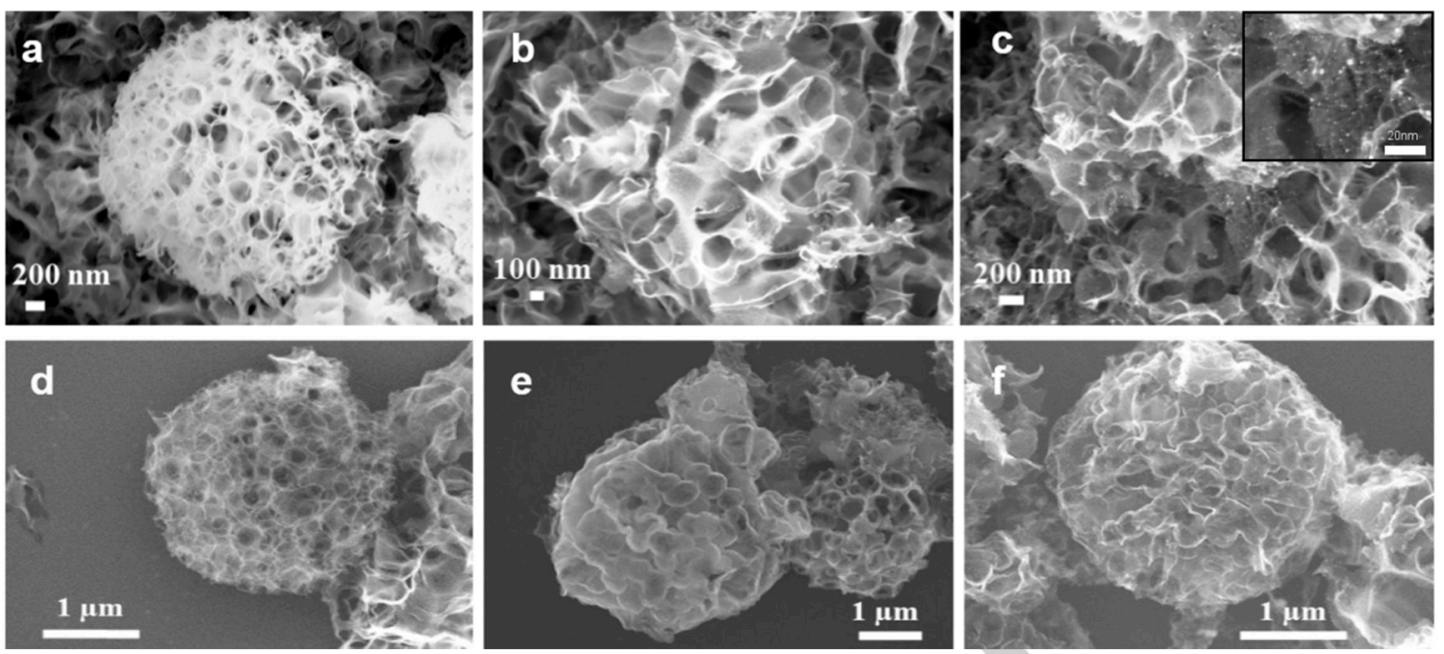

Figure 1. SEM images of catalysts prepared with different Pt contents and annealing temperatures (a) PtCM200-A500, (b) PtCM200-A700, (c) PtCM200-A900, (d) PtCM100-A500, (e) PtCM100-A700 and (f) PtCM100-A900.

electrocatalysts. Several approaches have been investigated to improve tolerance to methanol-crossover, including the use of alternative materials such as Ru-Se. ${ }^{[12]}$ However, an improvement in methanol tolerance often results in a decrease in activity in the ORR and, as a consequence, high metal loadings must be employed to offset this effect. Notably, Pt alloys with noble metals such as $\mathrm{Pd}$ or Ru have been shown to be tolerant to the presence of methanol while maintaining high activity in the ORR. ${ }^{[2 a, 13]}$ The use of polymer coatings as protective routes in order to address methanol crossover for ORR in Pt-based catalysts has been reported in literature ${ }^{[14]}$ However, this route add an extra step in the preparation of final electrocalysts, which is not desirable from a commercial point of view. Therefore, the improvement of synthesis methods in only one step for producing high active, durable and methanol tolerant Pt electrocatalysts is needed.

Moreover, the finding of a well-defined carbon support with desirable textural properties, controllable anti-corrosion and interaction with $\mathrm{Pt}$ nanoparticles would be very helpful for electrochemical applications. The use of carbon forms with high graphitic content, such as graphene or carbon nanotubes, as well as co-doping of the carbon matrix with heteroatoms have both been shown to improve corrosion resistance. ${ }^{[\mathrm{b},}{ }^{15]}$ It has been proposed that carbon could also improve the stability of $\mathrm{Pt}$ catalysts by preventing nanoparticle aggregation and dissolution ${ }^{[16]}$ A carbon coating or shell has been shown to improve Pt NP stability under high temperatures, ${ }^{[17]}$ to minimize $\mathrm{CO}$ poisoning ${ }^{[18]}$ and to minimise Pt leaching in solution. ${ }^{[19]}$ Several methods have been developed for the synthesis of carbon-embedded $\mathrm{Pt}$ nanoparticles, ${ }^{[18 \mathrm{~b}, 18 \mathrm{c}, 20]}$ however many of these require multiple steps or are not suitable for the preparation of electrode materials in large scale. Continuous flow methods offer an intrinsically scalable route to the preparation of materials for practical applications. For instance, Ernst et al. demonstrated that carbon encapsulated Pt nanoparticles could be prepared via flame spray pyrolysis using organic precursor solutions and tested their performance in cyclohexene hydrogenation. ${ }^{[18 a]}$ In this report we describe for the first time the application of continuous flow ultrasonic spray pyrolysis (USP) to the synthesis of active and highly durable Pt-based electrocatalysts for ORR in one step. Suslick and co-workers have developed methods for the USP synthesis of porous carbon microspheres (CMs) in the absence of hard templates, which result in carbon materials with high specific surface area ${ }^{[21]}$. Work from our group has also shown that thus synthesized CMs can be used as support for metal nanoparticles, ${ }^{[22]}$ and that USP methods can be used to prepare metal@CM electrocatalysts. ${ }^{[23]}$ In this work we demonstrate that $\mathrm{Pt}$ nanoparticles embedded in porous carbon microspheres (PtCM) can be directly prepared from aqueous precursors in the absence of hard templates using continuous USP; PtCMs were found to display excellent durability and mass activity for the ORR and outstanding tolerance to the methanol-crossover.

Table 1. Pt content of the catalysts extracted from the thermogravimetric analysis (TGA) recorder in air from room temperature to $900^{\circ} \mathrm{C}$.

\begin{tabular}{|c|c|c|c|}
\hline Sample & $\begin{array}{c}\text { Pt } \\
\text { wt.\% }\end{array}$ & Sample & $\begin{array}{c}\mathbf{P t} \\
\text { wt. } \%\end{array}$ \\
\hline PtCM200-A500 & 5.2 & PtCM100-A500 & 1.1 \\
\hline PtCM200-A700 & 13.0 & PtCM100-A700 & 3.5 \\
\hline PtCM200-A900 & 32.0 & PtCM100-A900 & 4.4 \\
\hline
\end{tabular}

\section{Results and Discussion}

\section{Structural characterization of PtCM materials}

Carbon microspheres were prepared via USP at a relatively low pyrolysis temperature of $500^{\circ} \mathrm{C}$; this initial low temperature was necessary to avoid water gas reactions catalysed at higher furnace temperatures that resulted in low or negligible yields of carbon particles. Two types of particles were prepared using 100 ppm and 200 ppm initial Pt-concentrations and subsequent annealing at two different temperatures, $700^{\circ} \mathrm{C}$ and $900^{\circ} \mathrm{C}$, under nitrogen flow and dry conditions resulted in six different 

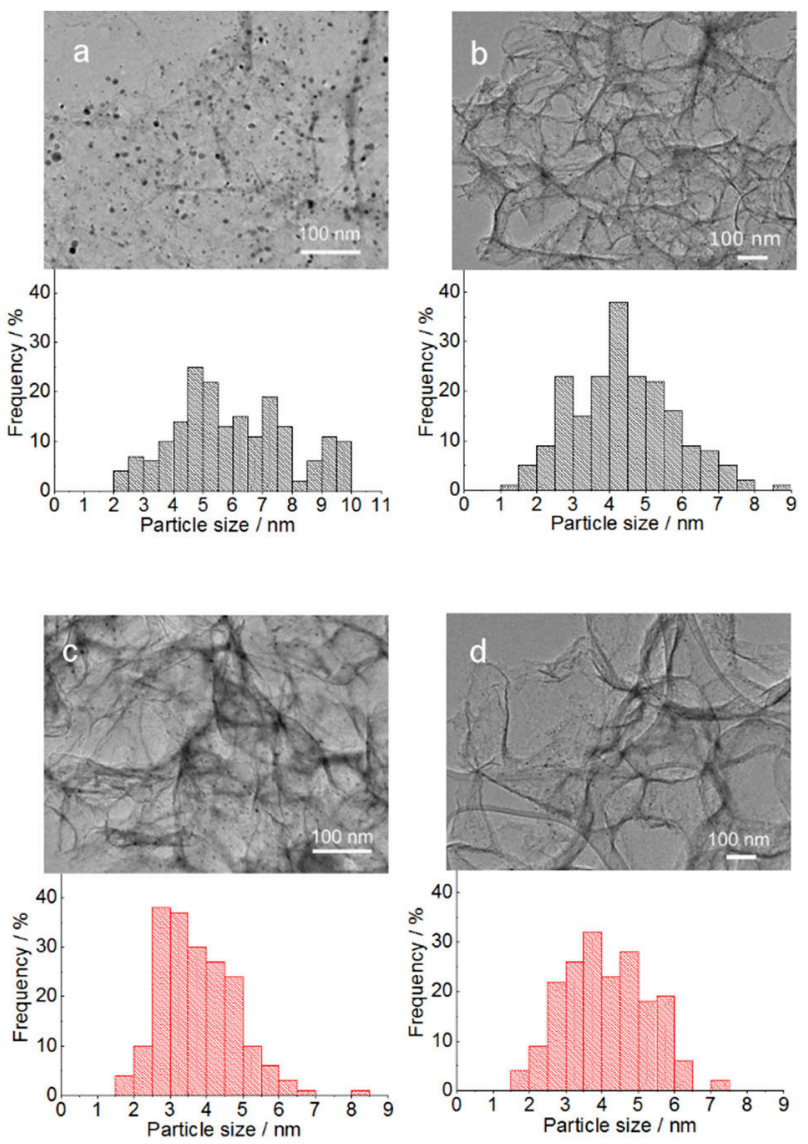

Figure 2. TEM images of the samples prepared after annealing treatments (a) PtCM200-A900, (b) PtCM200-A700, (c) PtCM100-A900and (d) PtCM100-A700.

materials, denoted as PtCM. The metal content of samples was determined by TGA.; Table 1 summarises the Pt content obtained from TGA curves. Samples are referred to the Pt concentration of the precursor solution (i.e. 100 or 200) and the final process temperature. As expected the final Pt loading of the samples is influenced by the amount of Pt used in the precursor: the higher the Pt-content in the precursor, the higher the final Pt loading at either of the annealing temperatures investigated. The amount of $\mathrm{Pt}$ in the final PtCM materials ranges from 1.1 to $32.0 \mathrm{wt}$. \%, and it is largest for the highest annealing temperature at either of the precursor concentrations.

Figure 1a-f shows SEM images of PtCM samples prepared under different temperature and concentration conditions. Images show that in the case of samples prepared at the lower Pt concentration, PtCM100, spherical particles were obtained at all temperatures, with diameters in the $1-3 \mu \mathrm{m}$ range (Figs. $1 \mathrm{~d}-\mathrm{f}$ ) and a morphology consistent with that observed when using sodium dichloroacetate in the USP precursor. ${ }^{[21 a, 22 a]}$ However, samples prepared using the higher Pt concentration, PtCM200, showed only well-defined spherical morphology when processed at $500^{\circ} \mathrm{C}$ (see Figure 1a), while at higher temperatures the morphology was ill-defined (Figs. $1 \mathrm{~b}, \mathrm{c})$. Cavities and large pores are evident in the carbon scaffold, while bright clusters that can
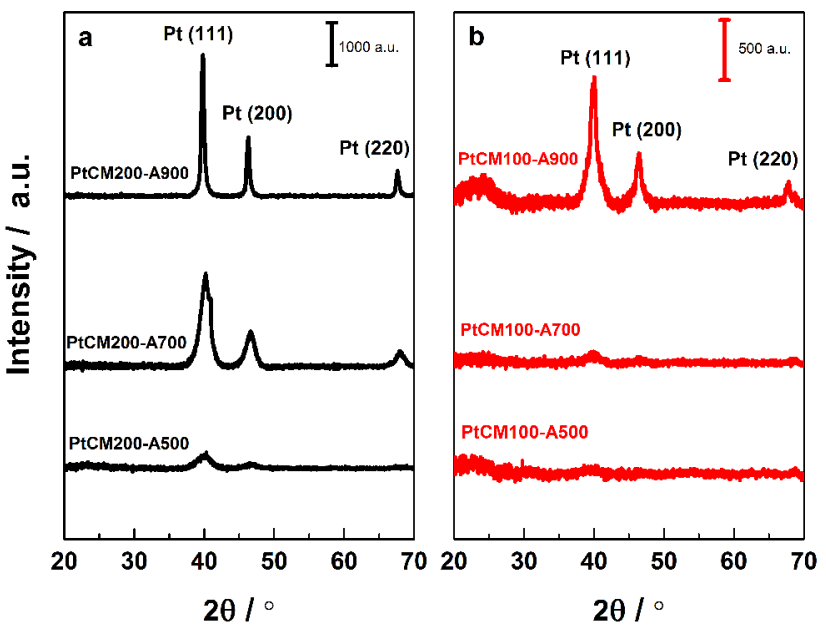

Figure 3. XRD patterns of (a) PtCM200 and (b) PtCM100 as prepared and after annealing.

be seen at the surface of Pt200-A900 (inset of Figure 1c) are consistent with the presence of metallic nanoparticles. Metal nanoparticles are not evident in the other PtCM samples via SEM, thus suggesting that any metallic nanoparticles formed are smaller in size than the SEM resolution and/or are embedded in the carbon phase.

TEM images of the samples subjected to annealing processes (Figure 2) show that Pt NPs also form in samples obtained with lower concentrations of $\mathrm{Pt}$ and at lower annealing temperatures and that Pt NPs are homogeneously distributed across the carbon scaffold. Figures $2 a$ and $2 b$ clearly show that samples prepared from $200 \mathrm{ppm}$ of the $\mathrm{Pt}$ salt as precursor result in higher concentrations of Pt NPs. The particle average diameter was found to be $4.4 \pm 1.4$ and $4.1 \pm 1.1 \mathrm{~nm}$ for Pt200-A700 and Pt100A700, respectively, thus indicating that particle diameter is not influenced by the amount of $\mathrm{Pt}$ used in the preparation after annealing at $700{ }^{\circ} \mathrm{C}$. However, for samples annealed at $900{ }^{\circ} \mathrm{C}$, the particle size shows a significant dependence on $\mathrm{Pt}$ concentration in the precursor, as PtCM200-A900 samples yielded an average NP size of $6.6 \pm 2.6 \mathrm{~nm}$ while Pt100-A900 resulted in a particle size of $3.8 \pm 1.0 \mathrm{~nm}$.

XRD patterns of PtCM samples are reported in Figure 3. PtCM200-A900 materials clearly show the characteristic peaks at $39.7^{\circ}, 46.3^{\circ}$ and $67.6^{\circ}$ corresponding to the (111), (200) and (220) reflections of face centred cubed (fcc) Pt (PDF No. 00-004-0802). Significant peak broadening is observed as the processing temperature is reduced along the series PtCM200 (black lines) thus indicating that crystallite size increases with temperature. Samples prepared at $100 \mathrm{ppm} \mathrm{Pt}$ concentrations in the precursor did not yield discernible peaks, except in the case of annealing at $900{ }^{\circ} \mathrm{C}$ (PtCM100-A900). The lack of any reflection peaks in PtCM100-A500 and PtCM100-A700 diffractograms indicates that nanoparticles evident from TEM images are likely to be amorphous. In summary, metallic $\mathrm{Pt}$ is the preferential crystalline phase resulting from the annealing process; formation of crystalline $\mathrm{Pt}^{0}$ is favoured by an increase in $\mathrm{Pt}$ concentration in the precursor and by an increase in processing temperature. 

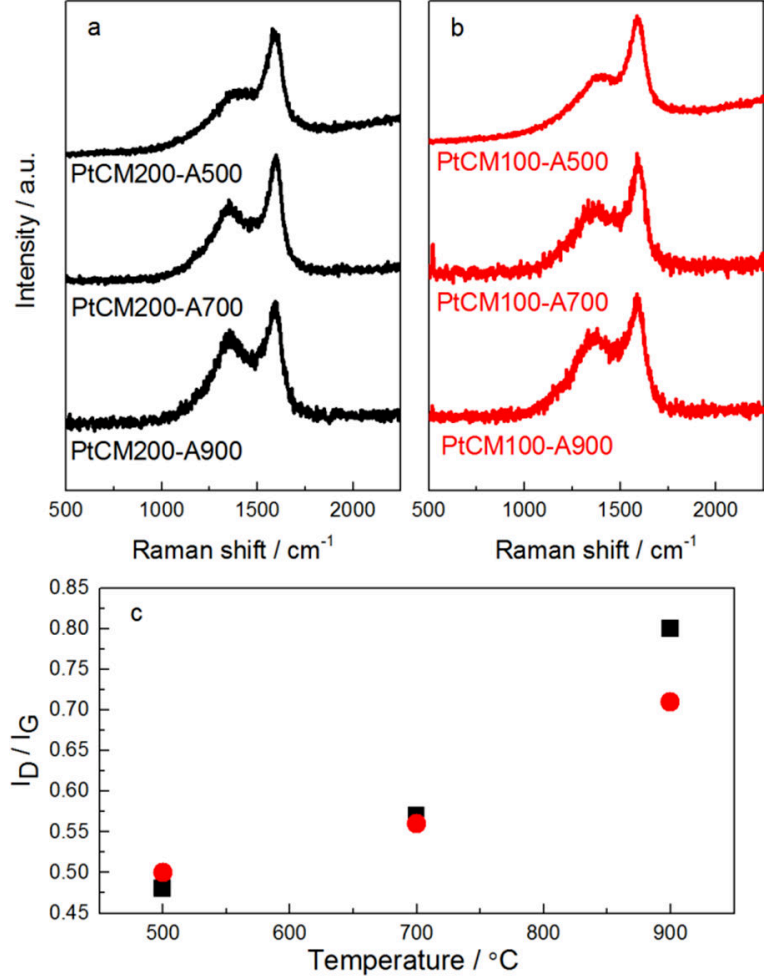

Figure 4. Raman spectra recorded for the catalysts prepared: (a) PtCM200 and (b) PtCM100. (c) Evolution of the ratio $\mathrm{I}_{\mathrm{D}} / \mathrm{I}_{\mathrm{G}}$ for catalysts PtCM200 (black squares) and PtCM100 (red circles).

Changes in the carbon phase with synthesis conditions were investigated using Raman spectroscopy. Figure 4a shows Raman spectra of synthesized samples, which display peaks at $\sim 1590$ $\mathrm{cm}^{-1}$ and $\sim 1370 \mathrm{~cm}^{-1}$ assigned to the $G$ and $D$ bands, respectively, of amorphous carbon. ${ }^{24]}$ The G-band is assigned to C-C stretching modes in $\mathrm{sp}^{2}$-rich carbons, while the $\mathrm{D}$-band is diagnostic of the presence of disordered graphitic clusters and arises from symmetry breaking of six-membered rings. To determine changes in spectral parameters, fits were carried out using two Gaussian functions corresponding to the $D$ and $G$ contributions; samples annealed at 700 and $900{ }^{\circ} \mathrm{C}$ required a third Gaussian contribution, denoted as A-band, ${ }^{[25]}$ which is attributed to $\mathrm{C}-\mathrm{C}$ stretching modes in amorphous regions that interconnect graphitic clusters (see Figure S1). Figure 4c shows a summary of fit results; the $I_{D} / l_{G}$ peak height ratio was found to increase with increasing processing temperature; this indicates an increase in the concentration of six-membered rings and is consistent with increased graphitic content in amorphous carbons [24]. It is interesting to note that the trends are almost identical for the two Pt concentrations studied; two-factor ANOVA ( $P$-value $=$ 0.02) confirmed that Pt content does not significantly affect total graphitic content in the carbon phase, while temperature is the dominant factor in determining the changes observed in the carbon phase.

The surface composition of PtCMs was studied via XPS; survey spectra (Figure S2) show the characteristic peaks associated with $\mathrm{C} 1 \mathrm{~s}, \mathrm{O} 1 \mathrm{~s}$ and $\mathrm{Pt} 4 \mathrm{f}$ lines. ${ }^{[26]}$ Spectra in the $\mathrm{C}$ 1s region (Figure S3) show a broad peak characteristic of amorphous carbon, ${ }^{[27]}$ whose width decreases as the processing temperature increases. This is consistent with graphitization of the carbon scaffold and is in agreement with Raman results. The $\mathrm{Pt} / \mathrm{C}$ at\% content of all materials was calculated from $A_{P_{t}} / A_{c}$ peak area ratios after correction for relative sensitivity factors. The $\mathrm{Pt} / \mathrm{C}$ at $\%$ surface content was found to be $0.2 \%$ and $0.4 \%$ for all samples prepared at 100 and 200 ppm, respectively, while no change in Pt/C content with process temperature was observed (Figure 5); this result therefore indicates that the surface content reflects the relative $\mathrm{Pt}$ concentration in the precursor solutions. These values resulted in an important reduction of at least half the amount of $\mathrm{Pt}$ at the surface of the catalysts in comparison of previous materials reported. ${ }^{[2 a, 28]}$ Surface Pt/C contents are equivalent to $3 \mathrm{wt} \%$ and
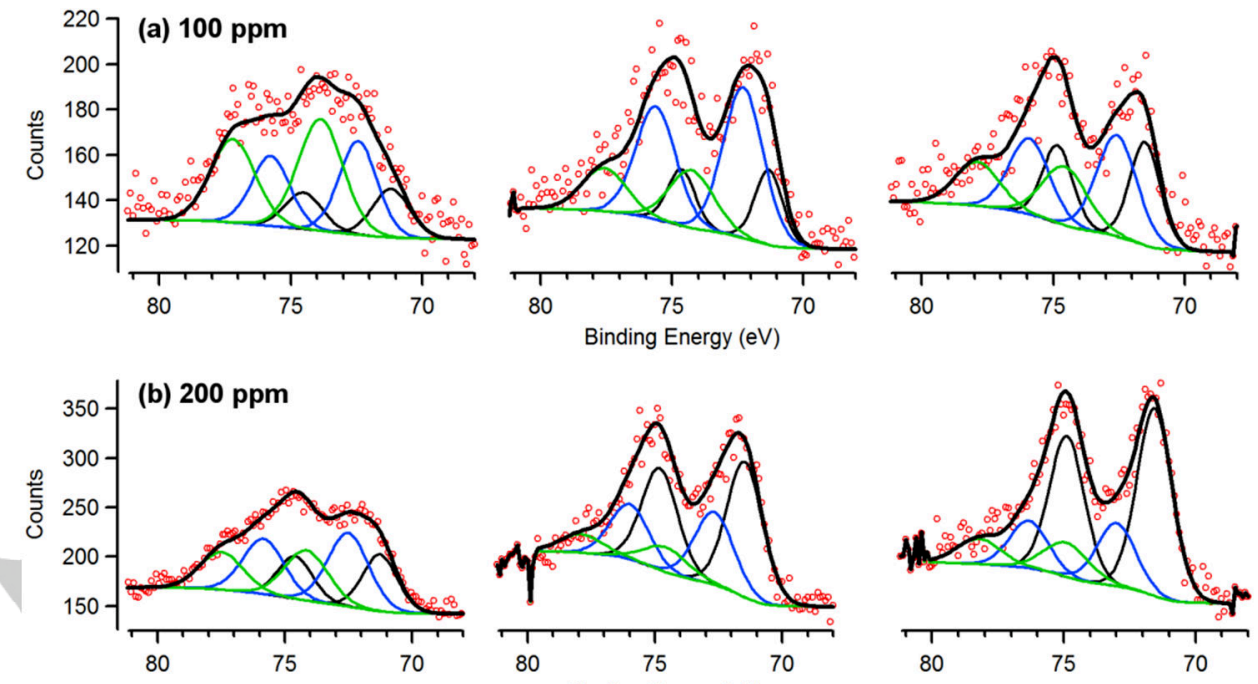

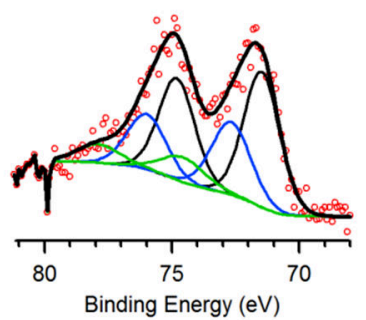

$700^{\circ} \mathrm{C}$

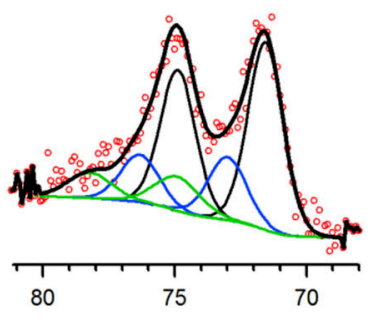

$900^{\circ} \mathrm{C}$

Figure 5. Pt $4 \mathrm{f}$ core-level spectra of (a) PtCM100and (b) PtCM200. Curve fitting is attributed to $\mathrm{Pt}^{\circ}$ (black lines), $\mathrm{Pt}(\mathrm{II})$ (blue lines) and $\mathrm{Pt}(\mathrm{IV})$ (green lines) contributions. 
and $6 \mathrm{wt} \%$; although this suggests a reasonable agreement with $\mathrm{Pt} \%$ content determined via TGA in the case of $100 \mathrm{ppm}$ concentration (Table 1), in the case of $200 \mathrm{ppm}$ it indicates that most of the Pt is buried in the carbon scaffold.

The Pt $4 \mathrm{f}$ core-level spectra for all PtCM materials synthesized is shown in Figure 5a-f; spectra show remarkable differences in composition among the different samples. Pt $4 \mathrm{f}$ fits included three different doublets $\left(4 f_{7 / 2}\right.$ and $4 f_{5 / 2}$ in $4: 3$ ratio) at approximately 71.3 , 72.4 and $74.2 \mathrm{eV}$, which are attributed to $\mathrm{Pt}^{\circ}, \mathrm{Pt}(\mathrm{II})$ and $\mathrm{Pt}(\mathrm{IV})$ contributions, respectively. ${ }^{[29]}$ Fits reveal that all samples possess $\mathrm{Pt}^{0}$ centres however the metallic proportion relative to total $\mathrm{Pt}$ content ranges from $17 \%$ to $62 \%$, and increases with increasing processing temperature as shown in Figure 5 . The proportion of $\mathrm{Pt}^{0}$ at the surface is extremely relevant to ORR electrocatalysis as $\mathrm{Pt}^{0}$ is more resistant to corrosion than $\mathrm{PtOx} ;{ }^{[30]} \mathrm{PtOx}$ centres are more unstable under acidic electrochemical environments and they are easily reduced and re-deposited over the support, resulting in Pt NP agglomeration and catalyst instability. However, PtOx resulting from the PtCM synthesis is expected to be easily reduced under the conditions used to test ORR activity described in the following section. ${ }^{[31]}$

\section{Electrochemical characterization of PtCM materials}

Figure 6a shows $\mathrm{CV}$ s of samples in Ar-saturated $0.1 \mathrm{M} \mathrm{HClO}_{4}$ at a scan rate of $10 \mathrm{mV} \mathrm{s}^{-1}$. The curves show the absence of defined faradaic peaks, however, for the two samples prepared at $900{ }^{\circ} \mathrm{C}$ the curves show increased currents over the 0.05-0.35 $\mathrm{V}_{\text {RHE }}$ region, associated with underpotential hydrogen adsorption/desorption; ${ }^{[31 a]}$ this suggests that catalytically active $\mathrm{Pt}^{0}$ might be present at the surface of these two samples. The absence of anodic currents in this region for samples prepared at $700{ }^{\circ} \mathrm{C}$ indicates that despite these samples containing similar $\mathrm{Pt} / \mathrm{C}$ at $\%$ as the corresponding ones prepared at $900{ }^{\circ} \mathrm{C}$, metal centres are less exposed at the electrolyte interface. Samples processed at $500{ }^{\circ} \mathrm{C}$ showed poor electrochemical conductivity and they will not be considered for electrochemical characterization from here onwards.

Figure $6 \mathrm{~b}$ shows ORR polarization curves of the catalysts (anodic branch) obtained in $\mathrm{O}_{2}$-saturated $0.1 \mathrm{M} \mathrm{HClO}_{4}$ at $10 \mathrm{mV} \mathrm{s}^{-1}$ and $1600 \mathrm{rpm}$, after subtraction of the corresponding capacitive currents. The onset potential $\left(E_{o n}\right)$ for the ORR was found to shift to more positive values as the amount of $\mathrm{Pt}$ and annealing temperature increase. Thus, PtCM200-A900 exhibits the highest activity for the ORR within the kinetically controlled region (0.8$1.0 V_{\text {RHE }}$, followed by PtCM200-A700, PtCM100-A900 and PtCM100-A700. The $E_{\text {on }}$ defined as the potential required for generating an ORR current density of $0.1 \mathrm{~mA} \mathrm{~cm}^{-2},{ }^{[32]}$ is of 0.99 $\mathrm{V}_{\mathrm{RHE}}$ for the most active catalyst, only $10 \mathrm{mV}$ lower than the onset observed for the benchmark Pt/C (20 wt.\%) catalyst. Moreover, the use of a Pt loading of $16 \mu \mathrm{gl}_{\mathrm{Pt}} \mathrm{cm}^{-2}$ for the PtCM100-A900

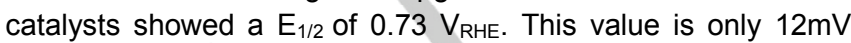
lower than recent activity reported in literature of $0.82 V_{R H E}$ using a Pt loading of $20 \mu \mathrm{g}_{\mathrm{Pt}} \mathrm{cm}^{-2}$. $\left.{ }^{[9 b}, 33\right]$ The current density increases exponentially with decreasing potential in the kinetic-controlled region, while at more negative potentials the current is controlled by mass transport, reaching a limiting cathodic current $>5.5 \mathrm{~mA}$ $\mathrm{cm}^{-2}$ that is close to the value expected from a $4 \mathrm{e}^{-}$reduction according to the Koutecky-Levich equation and comparable to
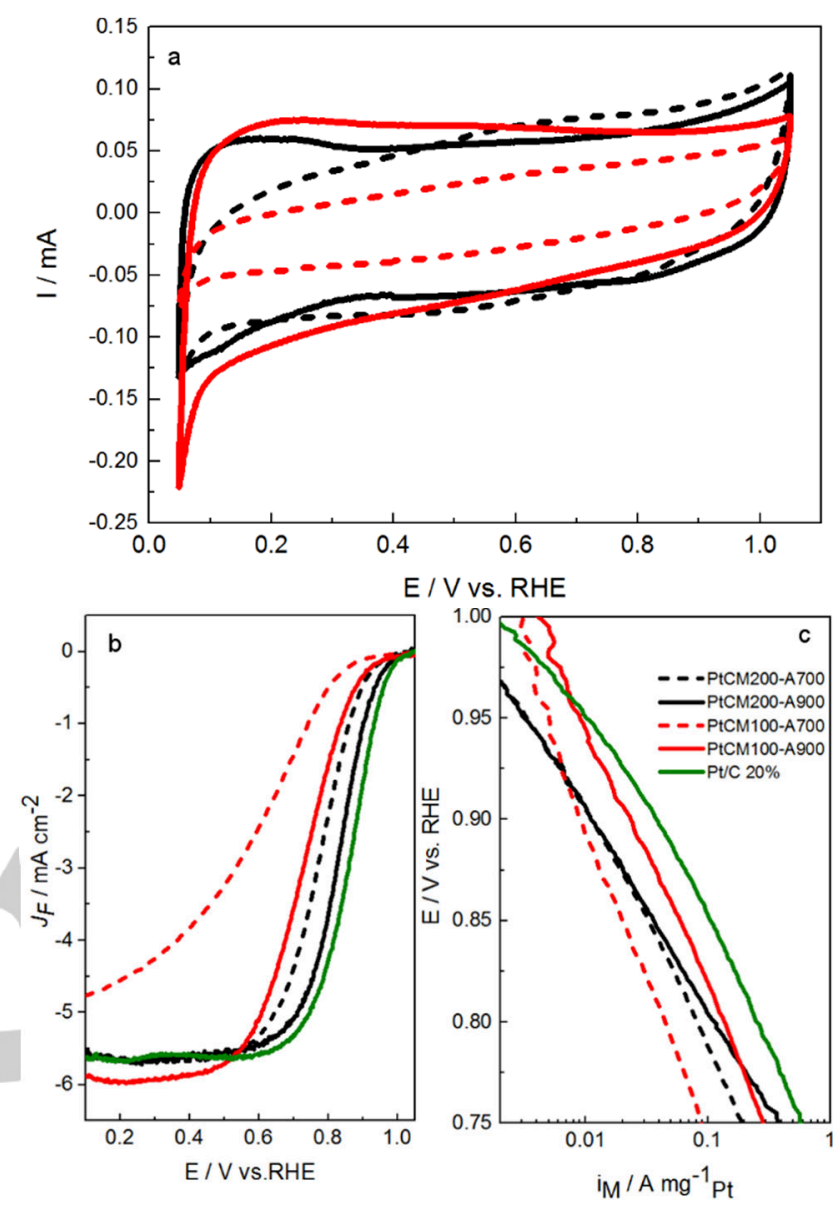

Figure 6. a) Cyclic voltammograms of Pt-based catalysts recorded in Arsaturated $0.1 \mathrm{M} \mathrm{HClO}_{4}$ at $10 \mathrm{mV} \mathrm{s}^{-1}$. (b) ORR polarization curves and (c) ORR mass activities recorded in $\mathrm{O}_{2}$-saturated $0.1 \mathrm{M} \mathrm{HClO}_{4}$ at $10 \mathrm{mV} \mathrm{s}^{-1}$ and 1600 rpm. PtCM200-A900 (black solid lines), PtCM200-A700 (black dashed lines), PtCM100-A900 (red solid lines), PtCM100-A700 (red dashed lines) and Pt/C (20 wt.\%).(green line).

values reported in literature. ${ }^{[6 b, 9 b, 33]}$ An exception is the PtCM100A700 sample which yields cathodic currents smaller than $5 \mathrm{~mA}$ $\mathrm{cm}^{-2}$, thus indicating that this material possesses the lowest ORR activity, possibly due to sites with low activity and/or to a low density of active sites.

Figure $6 \mathrm{c}$ shows the mass transport-corrected mass activities $\left(i_{M}\right)$ in the kinetically controlled region; these values are normalized by the bulk Pt content obtained from TGA curves. The activity is strongly influenced by the $\mathrm{Pt}$ content of the sample, being the catalysts PtCM100-A900 the most active for the ORR. This suggests that in PtCM100-A900, Pt sites possess greater activity compared to those obtained at higher concentrations.

Koutecky-Levich plots $\left(j^{-1}\right.$ versus $\left.\omega^{-1 / 2}\right)$ were used to calculate the number of electrons involved in the reduction pathway over the potential range of 0.1 to $0.5 \mathrm{~V}$ (Figure S4). The values were found to be 3.6, 2.6, 4.0 and 3.7 for PtCM100-A900, PtCM100-A700, PtCM200-A900 and PtCM200-A700, respectively, thus indicating that the ORR proceeds mostly through a $4 \mathrm{e}^{-}$reduction of the oxygen molecule in the most active catalysts studied. Tafel slopes calculated from plots of kinetic current densities $\left(j_{k}\right)$ vs. 


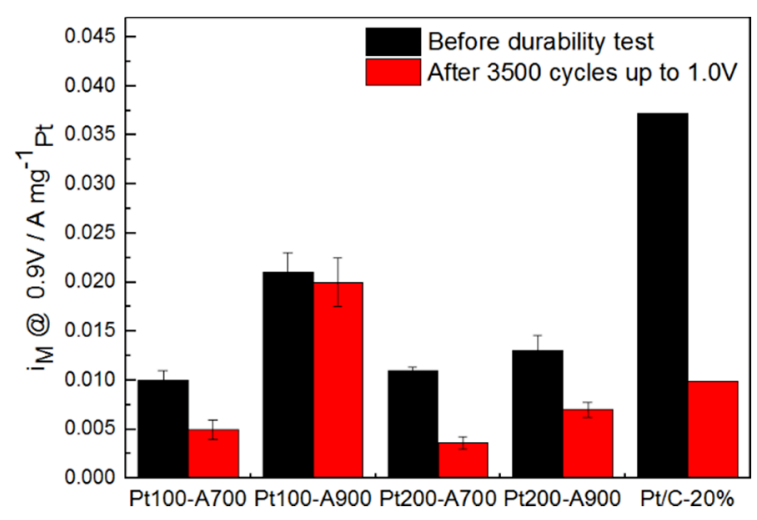

Figure 7. ORR mass activities in $0.1 \mathrm{M} \mathrm{HClO}_{4}$ at $10 \mathrm{mV} \mathrm{s}^{-1}$ and $1600 \mathrm{rpm}$ for the catalysts, before (black bars) and after (red bars) the stability tests: 3500 cycles between 0.6 and $1.0 \mathrm{~V}$ at $50 \mathrm{mV} \mathrm{s}^{-1}$
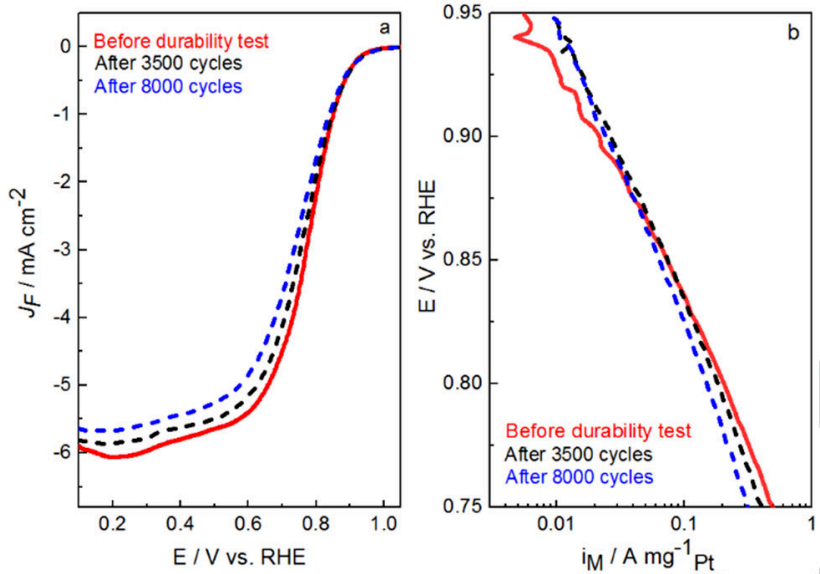

Figure 8. (a) ORR polarization curves and (b) ORR mass activities for the catalyst PtCM100-A900 recorded in $\mathrm{O}_{2}$-saturated $0.1 \mathrm{M} \mathrm{HClO}_{4}$ at $10 \mathrm{mV} \mathrm{s}^{-1}$ and $1600 \mathrm{rpm}$ before (red line), after 3500 cycles (black line) and after 8000 cycles (blue line) between 0.6 and $1.0 \mathrm{~V}$ at $50 \mathrm{mV} \mathrm{s}^{-1}$.

overpotential $(\eta)$ yielded values ranging from 64 to $88 \mathrm{mV} \mathrm{dec}^{-1}$ in agreement with previous results on $\mathrm{Pt} / \mathrm{C}$ catalysts under acidic conditions, ${ }^{[34]}$ (Table S1). Finally, current exchange densities (jo) showed higher values in catalysts with the lowest Pt content, suggesting a higher intrinsic activity of the active sites formed in PtCM100-A700 and PtCM100-A900 in agreement with results from mass activity plots in Figure 6c.

To study catalyst stability we performed an accelerated stability test consisting in 3500 consecutive cycles between 0.6 and $1.0 \mathrm{~V}$ at $50 \mathrm{mV} \mathrm{s}^{-1}$ in $\mathrm{O}_{2}$-saturated $0.1 \mathrm{M} \mathrm{HClO}_{4}$. Figure 7 shows the mass activity of the catalysts before and after the durability test. The loss of mass activity is more evident in samples prepared from $200 \mathrm{ppm}$ of $\mathrm{Pt}$ in the precursor, than in the samples with a lower $\mathrm{Pt}$ content. When examining the effect of processing temperature, the loss of activity is smaller for catalysts annealed at the $900{ }^{\circ} \mathrm{C}$, which were also found to be the most active samples in the series: the loss in $i_{M}$ at $0.9 \mathrm{~V}_{\mathrm{RHE}}$ was found to be $5 \%$ and $46 \%$ for PtCM100-A900 and PtCM200-A900, respectively The stability of catalysts studied is higher than that of the benchmark Pt/C (20 wt.\%) catalyst which records a severe mass
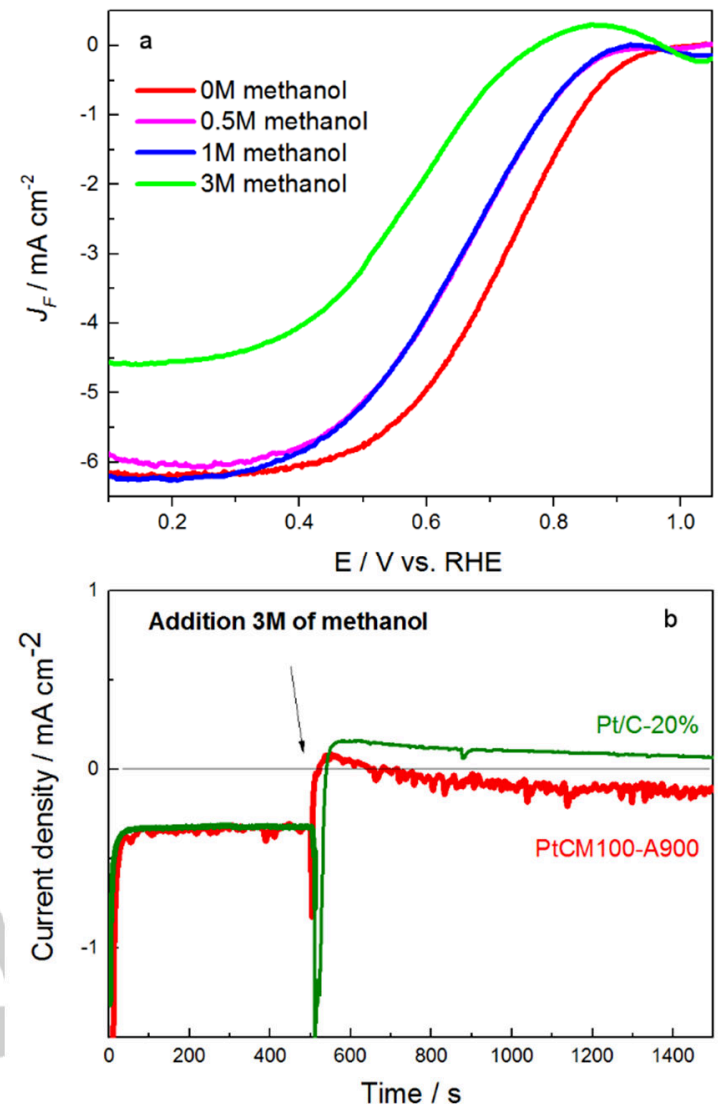

Figure 9. (a) ORR polarization curves for the $\mathrm{PtCM} 100-\mathrm{A} 900$ catalyst in an $\mathrm{O}_{2}$ saturated $0.1 \mathrm{M} \mathrm{HClO}_{4}$ at $10 \mathrm{mV} \mathrm{s}^{-1}$ and $1600 \mathrm{rpm}$. And varying methanol concentration: $0 \mathrm{M}$ (red), $0.5 \mathrm{M}$ (magenta), $1 \mathrm{M}$ (blue) and $3 \mathrm{M}$ (green). (b) Chronoamperometric response of PtCM100-A900 (red) and $\mathrm{Pt} / \mathrm{C}$ (20 wt.\%) (green) in $\mathrm{O}_{2}$-saturated $0.1 \mathrm{M} \mathrm{HClO}_{4}$ electrolyte at $0.55 \mathrm{~V}$.

activity loss of ca. $70 \%$ at $0.9 \mathrm{~V}$ after cycling at same conditions. The higher stability observed for PtCM100-A900 can be likely attributed to a combination of greater dispersion and embedding of $\mathrm{Pt}$ nanoparticles within the carbon matrix, which can act as a protective layer for nanoparticle dissolution/aggregation. Furthermore, the higher annealing temperatures (i.e. $900{ }^{\circ} \mathrm{C}$ ) result in greater graphitic content in the carbon scaffold, which is known to promote durability in the ORR, as previously reported. [15] As observed in Figure 7, the PtCM100-A900 catalyst displayed stable behaviour after 3500 consecutive cycles in $\mathrm{O}_{2}$-saturated electrolyte; therefore, a longer durability test up to 8000 consecutive cycles under the same conditions was carried out for this sample. Figure $8 \mathrm{a}$ and $8 \mathrm{~b}$ show the ORR polarization curves and the mass transport corrected mass activities (iM) in the kinetically-controlled region for PtCM100-A900 before and after the durability tests. The catalyst was found to exhibit a high resistance to degradation maintaining an identical onset potential before and after the cycling. The activity of this catalyst is as stable as other materials reported after applying similar conditions in the accelerated degradation test (ADT). ${ }^{\left[{ }^{[b}, 6 b\right]}$ Remarkably, the mass activity evaluated in the kinetic region at $0.9 \mathrm{~V}_{\mathrm{RHE}}$ results in the same value of $0.022 \pm 0.002 \mathrm{~A} \mathrm{mg} \mathrm{pt}^{-1}$ before and after 8000 consecutive cycles. These results suggest that the use of carbon 
microspheres as the support for Pt nanoparticles is a successful method for the preparation of stable Pt-based catalysts for the ORR, even with a low amount of the metal being catalytically active. Furthermore, the use of lower concentrations of metal precursor results in the formation of smaller $\mathrm{Pt}$ nanoparticles and better dispersion within the carbon phase, based on TEM images. The application of Pt-based catalysts as cathode electrodes in DMFCs is dependent on their tolerance to the methanol crossover Methanol from the anode may permeate through the polymer membrane to the cathode, causing a severe decay in the performance of the catalysts for the ORR due to the use of active sites for methanol oxidation and progressive $\mathrm{CO}$ poisoning of $\mathrm{Pt}$ surfaces. To test whether carbon microsphere embedding also protects against crossover the most active and durable catalyst, PtCM100-A900 was subjected to methanol tolerance tests in $\mathrm{O}_{2^{-}}$ saturated $0.1 \mathrm{M} \mathrm{HClO}_{4}$ by adding different concentrations of methanol during the ORR reaction. Figure 9a shows that the performance of PtCM100-A900 is only slightly affected by the addition of methanol in the $0.5-1 \mathrm{M}$ range, which is significantly higher than expected at the cathode during DMFC cell operation. ${ }^{[35]}$ Only after the addition of $3 \mathrm{M}$ of methanol the performance is significantly affected and positive current values are recorded in the region of 0.75-0.95 $\mathrm{V}_{\mathrm{RHE}}$; notably, this concentration is higher than those typically used in the literature for tolerance tests. The ORR remains the predominant process even in the presence of $3 \mathrm{M}$ of methanol in the electrolyte, as evidenced from the net negative current densities in Figure 9a. The tolerance of PtCM100-A900 to methanol crossover at low potentials after the addition of $3 \mathrm{M}$ of methanol was also probed at a constant potential of $0.55 \mathrm{~V}_{\mathrm{RHE}}$ via a current-time (i-t) chronoamperometric method under ORR conditions. Figure $9 \mathrm{~b}$ shows that, upon addition of $3 \mathrm{M}$ of methanol in solution, only a minor change of $0.2 \mathrm{~mA} \mathrm{~cm}{ }^{-2}$ is observed for PtCM100-A900; therefore the initial cathodic current is not significantly affected by methanol addition. In particular, the current value recorded for PtCM100-A900 after the addition of methanol remains always negative, indicating that no other reactions than oxygen reduction take place at the cathode, i.e. no methanol oxidation reaction occurs at the cathode. The tolerance of our catalyst to the addition of methanol under ORR conditions is clearly better than the benchmark of $\mathrm{Pt} / \mathrm{C}$ (20 wt.\%) catalyst, in which positive currents were recorded during the chronoamperometric method.

These results clearly suggest that the catalyst PtCM100-A900 exhibits an excellent selectivity for the ORR thus being superior to the commercial $\mathrm{Pt} / \mathrm{C}$ catalysts. Their methanol tolerance was found to be comparable to that of recently reported Pt-free materials, ${ }^{[36]}$ and to that of Pt alloys, ${ }^{[37]}$ This suggests that the carbon matrix has a protective effect on Pt activity, likely reducing aggregation, dissolution and poisoning degradation pathways.

\section{Conclusions}

In this study, we report the first continuous flow synthesis of $\mathrm{Pt}$ nanoparticles embedded in carbon microspheres. The method involves ultraspray pyrolysis of a Pt-containing aqueous mist in a flow reactor and results in one-step synthesis of carbon stabilized
Pt clusters. Therefore, this synthetic route offers an intrinsically scalable methodology for the preparation of complex, nanostructured $\mathrm{Pt} / \mathrm{C}$ electrode materials. Results showed that the post-annealing treatment of the catalysts at 700 and $900{ }^{\circ} \mathrm{C}$ increases crystallinity of the Pt nanoparticles ant the content of metallic Pt at the surface. Moreover, Raman results confirmed a higher level of carbon graphitization after the annealing process, especially after the treatment at $900{ }^{\circ} \mathrm{C}$. Electrochemical measurements showed that the catalytic activity in the oxygen reduction reaction is influenced by $\mathrm{Pt}$ content and graphitization level of the carbon, resulting in the highest activity for samples annealed at higher temperatures. Remarkably, the best overall catalytic performance in terms of mass activity and durability was conducted with a loading of only $16 \mu \mathrm{gPt}_{\mathrm{Pt}} \mathrm{cm}^{-2}$ of $\mathrm{Pt}$, which is in the range of low and ultra-low Pt loadings. ${ }^{[3]}$ Moreover, the combination of low Pt content and high graphitic carbon scaffold results in highly durable electrocatalysts for the oxygen reduction reaction with excellent tolerance to methanol crossover. The enhancement in the properties of the catalysts prepared in terms of durability and tolerance to methanol impurities might be attributed to a protective effect of the carbon scaffold, allowing at the same time the ORR activity of Pt nanoparticles. Our results therefore confirm that continuous flow synthesis via ultraspray pyrolysis offers a viable and scalable synthetic strategy for generating porous catalysts with reduced Pt-content, improved durability and enhanced methanol tolerance.

\section{Experimental Section}

Synthesis of the catalysts. Pt NPs embedded in carbon microspheres (PtCMs) were synthesized using ultrasonic spray pyrolysis (USP) using a setup as previously described. ${ }^{[21 a, 22 a]}$ Briefly, a $1.5 \mathrm{M}$ solution of potassium dichloroacetate containing either $0.001 \mathrm{M}$ potassium tetrachloroplatinate (200 ppm $\mathrm{Pt}$ ) or $0.0005 \mathrm{M}$ potassium tetrachloroplatinate $(100 \mathrm{ppm} \mathrm{Pt}$ ) was nebulized using a $1.7 \mathrm{MHz}$ piezoelectric disk. The resulting mist was carried into a quartz tube furnace using a nitrogen gas flow, where pyrolysis occurred at $500{ }^{\circ} \mathrm{C}$. The resulting carbon microspheres were captured in a water bubbler, then isolated by filtration over a $0.45 \mu \mathrm{m}$ nylon filter, and finally washed thoroughly with deionized water, methanol, and acetone. The synthesized particles were annealed under nitrogen: particles were heated to $200{ }^{\circ} \mathrm{C}$ at $10{ }^{\circ} \mathrm{C} \mathrm{min}-1$, then held for $30 \mathrm{~min}$ to remove excess water and solvent, subsequently heated to 700 or $900{ }^{\circ} \mathrm{C}$ at $10{ }^{\circ} \mathrm{C} \mathrm{min}^{-1}$, and finally held at these final temperatures for $60 \mathrm{~min}$. Following annealing the particles were cooled to room temperature under nitrogen flow.

Structural characterization. Metal loading was determined using thermogravimetric analysis (TGA, TA Instruments Q50). Samples were heated in dry air to $900{ }^{\circ} \mathrm{C}$ at a rate of $10^{\circ} \mathrm{C} \mathrm{min}-1$, including a constant temperature interval at $200{ }^{\circ} \mathrm{C}$ to ensure solvent desorption. At least $1 \mathrm{mg}$ of sample was used in all TGA measurements and masses were normalized to the sample weight at $200{ }^{\circ} \mathrm{C}$. Scanning electron microscopy (SEM) was carried out on a Karl Zeiss Ultra-Field Emission SEM at 2-15 $\mathrm{kV}$ accelerating voltage and a working distance between 1 and $5 \mathrm{~mm}$. Transmission electron microscopy (TEM) was carried out on a JEOL JEM model FEl Titan at $200 \mathrm{kV}$. X-ray diffraction (XRD) patterns were collected on a Bruker D2 Phaser with a Cu Ka source $(\lambda=1.5418 \AA)$ generated at 40 $\mathrm{kV}$ and $40 \mathrm{~mA}$; data were recorded at $0.02 \%$ for $2 \theta$ values between $20^{\circ}$ and $70^{\circ}$. All Raman spectroscopy measurements were performed using a 
Renishaw 1000 micro-Raman system (with a $488 \mathrm{~nm}$ excitation wavelength from $\mathrm{Ar}^{+}$laser, a power of $5 \mathrm{~mW}$ and a spot size of approximately $3 \mu \mathrm{m}$ ) X-ray photoelectron spectroscopy (XPS) spectra were obtained on a VG Scientific ESCALab MKII system with an AI Ka Xray source $(1486.7 \mathrm{eV})$. For survey scans, an analyser pass energy of 200 $\mathrm{eV}$ was used, whereas a pass energy of $20 \mathrm{eV}$ was used to obtain core level spectra. Analysis was carried our using commercial software (CasaXPS); spectra were Shirley-background corrected and referenced to the $\mathrm{C}$ 1s line at $284.6 \mathrm{eV}$, while peaks were fitted to Voigt line contributions. Peak areas were used to calculate at $\%$ content after correction for relative sensitivity factors $(\mathrm{RSF}(\mathrm{Pt}) / \mathrm{RSF}(\mathrm{C})=17.6)$.

Electrochemical characterization. Electrochemical experiments were performed with a potentiostat/galvanostat (Autolab Pgstat 302N) using a standard three-electrode cell thermostated at $25{ }^{\circ} \mathrm{C}$ and a rotating disk electrode (RDE, Pine). The counter electrode was a graphite rod, the reference electrode was a Hydroflex electrode (Gaskatel) and the working electrode consisted of a glassy carbon disk with the electrocatalyst under study. The electrocatalyst was deposited on the previously polished glassy carbon electrode via drop casting of $20 \mu \mathrm{L}$ of an ink containing the electrocatalyst in suspension. Inks were prepared using $1.8 \mathrm{mg}$ of the catalyst in $400 \mu \mathrm{L}$ of Milli-pore water, $100 \mu \mathrm{L}$ of isopropyl alcohol and 10 $\mu \mathrm{L}$ of $5 \mathrm{wt} . \%$ Nafion 117 followed by ultrasonication; this resulted in a catalyst loading of $0.36 \mathrm{mgcat}_{\mathrm{cm}} \mathrm{cm}^{-2}$ for all samples tested.

Prior to testing, working electrodes were cleaned via potential cycling from 0.05 to $1.1 \mathrm{~V}$ vs. RHE in Ar-saturated $0.1 \mathrm{M} \mathrm{HClO}_{4}$ (20 cycles). ORR polarization curves were obtained in $\mathrm{O}_{2}$-saturated $0.1 \mathrm{M} \mathrm{HClO}_{4}$ electrolyte over the $0.05-1.05 \mathrm{~V}$ range at $10 \mathrm{mV} \mathrm{s}^{-1}$ and at 400,900 and $1600 \mathrm{rpm}$; subsequently, cyclic voltammograms (CVs) were collected in Ar-saturated $0.1 \mathrm{M} \mathrm{HClO}_{4}$ under identical conditions. Faradaic current densities $j_{\mathrm{F}} \mathrm{mA}$ $\mathrm{cm}^{-2}$ ) were obtained by subtracting the capacitive current obtained in $\mathrm{Ar}$ saturated electrolyte from that obtained in $\mathrm{O}_{2}$-saturated electrolyte under identical experimental conditions. ORR kinetic currents $i_{k}(A)$ were calculated as $i_{k}=i_{F} \times i_{\text {lim }} /\left(i_{\text {lim }}-i_{F}\right)$ where $i_{\text {lim }}$ is the cathodic limiting current. Finally, the ORR mass activity was obtained from $i_{M}=-i_{k} / m_{P t}$ where $m_{P t}$ is the total Pt loading expressed in grams. ${ }^{[34 b]}$ Stability tests were carried out by cycling the electrode between 0.6 and $1.0 \mathrm{~V}$ at $50 \mathrm{mV} \mathrm{s}^{-1}$ for 3000 cycles in $\mathrm{O}_{2}$-saturated electrolyte without rotation. The ORR polarization curves were collected before and after the stability tests following the procedure described above.

\section{Acknowledgements}

This publication has emanated from research conducted with the financial support of Science Foundation Ireland (SFI) grant No. 13/CDA/2213; MPB and LET also acknowledge support from SFI Grant No. 12/RC/2278 and 12/RC/2302; SL acknowledges support from the Irish Research Council Grant No. GOIPD/2014/68. KMM and CKL also acknowledge a grant from the Hewlett-Mellon Fund for Faculty Development at Albion College, Albion. MI. The authors are grateful to the staff in the AML, CRANN for help with SEM and TEM analysis, particularly D. Daly and E. McCarthy. We would also like to thank Dr. B. Twamley for help with the

Keywords: methanol fuel cell; Pt nanoparticles; durability; electrocatalysis; nanocatalysis.
[1] H. A. Gasteiger, S. S. Kocha, B. Sompalli, F. T. Wagner, Appl. Catal., B 2005, 56, 9-35.

[2] a) R. Escudero Cid, J. L. Gómez de la Fuente, S. Rojas, J. L. García Fierro, P. Ocón, ChemCatChem 2013, 5, 3680-3689; b) A. S. Aricò, S. Srinivasan, V. Antonucci, Fuel Cells 2001, 1, 133-161.

[3] a) J. Greeley, I. E. L. Stephens, A. S. Bondarenko, T. P. Johansson, H. A. Hansen, T. F. Jaramillo, J. Rossmeisl, I. Chorkendorff, J. K. Nørskov, Nature Chem. 2009, 1, 552-556; b) M. Escudero-Escribano, A. Verdaguer-Casadevall, P. Malacrida, U. Grønbjerg, B. P. Knudsen, A. K Jepsen, J. Rossmeisl, I. E. L. Stephens, I. Chorkendorff, J. Am. Chem. Soc. 2012, 134, 16476-16479; c) C. Chen, Y. Kang, Z. Huo, Z. Zhu, W. Huang, H. L. Xin, J. D. Snyder, D. Li, J. A. Herron, M. Mavrikakis, M. Chi, K. L. More, Y. Li, N. M. Markovic, G. A. Somorjai, P. Yang, V. R. Stamenkovic, Science 2014, 343, 1339-1343.

[4] H. A. Gasteiger, N. M. Marković, Science 2009, 324, 48-49.

[5] S. Sui, X. Wang, X. Zhou, Y. Su, S. Riffat, C.-j. Liu, J. Mater. Chem. A 2017, 5, 1808-1825.

[6] a) V. Mazumder, M. Chi, K. L. More, S. Sun, J. Am. Chem. Soc. 2010 132, 7848-7849; b) X. Huang, Z. Zhao, L. Cao, Y. Chen, E. Zhu, Z. Lin, M. Li, A. Yan, A. Zettl, Y. M. Wang, X. Duan, T. Mueller, Y. Huang, Science 2015, 348, 1230-1234; c) K. A. Kuttiyiel, K. Sasaki, Y. Choi, D. Su, P. Liu, R. R. Adzic, Energy Environ. Sci. 2012, 5, 5297-5304.

[7] a) D. Sebastián, A. G. Ruiz, I. Suelves, R. Moliner, M. J. Lázaro, V. Baglio, A. Stassi, A. S. Aricò, Appl. Catal., B 2012, 115-116, 269-275 b) S.-M. Hwang, Y Choi, M. G. Kim, Y.-J. Sohn, J. Y Cheon, S. H. Joo, S.-D. Yim, K. A. Kuttiyiel, K. Sasaki, R. R. Adzic, G.-G. Park, J. Mater. Chem. A 2016, 4, 5869-5876.

[8] J. X. Wang, H. Inada, L. Wu, Y. Zhu, Y. Choi, P. Liu, W.-P. Zhou, R. R. Adzic, J. Am. Chem. Soc. 2009, 131, 17298-17302.

[9] a) G. P. Keeley, S. Cherevko, K. J. J. Mayrhofer, ChemElectroChem 2016, 3, 51-54; b) W. S. Jung, B. N. Popov, Catal. Today 2017, 295, 6574.

[10] S. Maass, F. Finsterwalder, G. Frank, R. Hartmann, C. Merten, J. Power Sources 2008, 176, 444-451.

[11] D. Wang, Y. Yu, H. L. Xin, R. Hovden, P. Ercius, J. A. Mundy, H. Chen, J. H. Richard, D. A. Muller, F. J. DiSalvo, H. D. Abruña, Nano Lett. 2012 $12,5230-5238$.

[12] a) M. Montiel, S. García-Rodríguez, P. Hernández-Fernández R. Díaz, S. Rojas, J. L. G. Fierro, E. Fatás, P. Ocón, J. Power Sources 2010, 195 2478-2487; b) A. A. Serov, M. Min, G. Chai, S. Han, S. Kang, C. Kwak, J. Power Sources 2008, 175, 175-182.

[13] K. G. Nishanth, P. Sridhar, S. Pitchumani, A. K. Shukla, J. Electrochem. Soc. 2011, 158, B871-B876.

[14] Z. Yang, N. Nakashima, Sci. Rep. 2015, 5.

[15] C. Domínguez, F. J. Pérez-Alonso, M. A. Salam, S. A. Al-Thabaiti, M. A. Peña, F. J. García-García, L. Barrio, S. Rojas, Appl. Catal., B 2016, 183, 185-196.

[16] H. Suzuki, T. Sato, K. Kamitsuji, S. Kaneko, H. Kawasaki, C. Kaito, J. Cryst. Growth 2004, 268, 238-241.

[17] S. Hitoshi, S. Masayuki, S. Takeshi, T. Masayuki, M. Toyoaki, H. Michio, K. Chihiro, Jpn. J. Appl. Phys. 2005, 44, L610.

[18] a) F. O. Ernst, R. Büchel, R. Strobel, S. E. Pratsinis, Chem. Mater. 2008 20, 2117-2123; b) Z. Wen, J. Liu, J. Li, Adv. Mater. (Weinheim, Ger.) 2008, 20, 743-747; c) W. C. Choi, S. I. Woo, M. K. Jeon, J. M. Sohn, M. R. Kim, H. J. Jeon, Adv. Mater. (Weinheim, Ger.) 2005, 17, 446-451.

[19] K. Scholz, J. Scholz, A. James McQuillan, G. Wagner, O. Klepel, Carbon 2010, 48, 1788-1798.

[20] a) M. R. Callstrom, T. X. Neenan, R. L. McCreery, D. C. Alsmeyer, J. Am. Chem. Soc. 1990, 112, 4954-4956; b) T. You, O. Niwa, T. Horiuchi, M. Tomita, Y. Iwasaki, Y. Ueno, S. Hirono, Chem. Mater. 2002, 14, 47964799; c) L. Zhang, B. Cheng, E. T. Samulski, Chem. Phys. Lett. 2004 398, 505-510; d) K. Cheng, Z. Kou, J. Zhang, M. Jiang, H. Wu, L. Hu, X. Yang, M. Pan, S. Mu, J. Mater. Chem. A 2015, 3, 14007-14014.

[21] a) S. E. Skrabalak, K. S. Suslick, J. Am. Chem Soc. 2006, 128, 12642 12643; b) M. E. Fortunato, M. Rostam-Abadi, K. S. Suslick, Chem. Mater. 2010, 22, 1610-1612.

[22] a) P. Duffy, L. A. Reynolds, S. E. Sanders, K. M. Metz, P. E. Colavita Mater. Chem. Phys. 2013, 140, 343-349; b) K. M. Metz, S. E. Sanders, J. P. Pender, M. R. Dix, D. T. Hinds, S. J. Quinn, A. D. Ward, P. Duffy, R. J. Cullen, P. E. Colavita, ACS Sus. Chem. Eng. 2015, 3, 1610-1617.

[23] S. Marzorati, J. M. Vasconcelos, J. Ding, M. Longhi, P. E. Colavita, J. Mater. Chem. A 2015, 3, 18920-18927.

[24] A. C. Ferrari, J. Robertson, Phys. Rev. B 2000, 61, 14095-14107.

[25] a) D. Das, K. H. Chen, S. Chattopadhyay, L. C. Chen, J. Appl. Phys. 2002, 91, 4944-4955; b) N. Laidani, L. Guzman, A. Miotello, R. S. Brusa, G. P. Karwasz, A. Zecca, C. Bottani, J. Perrière, Nucl. Instrum. Methods Phys. Res., Sect. B 1997, 122, 553-558.

[26] C. D. Wagner, G. E. Muilenberg, Handbook of x-ray photoelectron spectroscopy: a reference book of standard data for use in $x$-ray 
photoelectron spectroscopy, Physical Electronics Division, Perkin-Elmer Corp., 1979.

[27] J. C. Lascovich, R. Giorgi, S. Scaglione, Appl. Surf. Sci. 1991, 47, 17-21.

[28] A. O. Al-Youbi, J. L. Gómez de la Fuente, F. J. Pérez-Alonso, A. Y. Obaid, J. L. G. Fierro, M. A. Peña, M. Abdel Salam, S. Rojas, Appl. Catal., B 2014, 150-151, 21-29.

[29] C. R. Parkinson, M. Walker, C. F. McConville, Surf. Sci. 2003, 545, 1933.

[30] Z.-Z. Jiang, Z.-B. Wang, Y.-Y. Chu, D.-M. Gu, G.-P. Yin, Energy Environ. Sci. 2011, 4, 2558-2566.

[31] a) S. Cherevko, A. R. Zeradjanin, G. P. Keeley, K. J. J. Mayrhofer, J. Electrochem. Soc. 2014, 161, H822-H830; b) S. Shibata, M. P. Sumino, Electrochim. Acta 1981, 26, 517-523.

[32] G. Wu, K. L. More, C. M. Johnston, P. Zelenay, Science 2011, 332, 443447.

[33] E. Fabbri, S. Taylor, A. Rabis, P. Levecque, O. Conrad, R. Kötz, T. J. Schmidt, Chem CatChem 2014, 6, 1410-1418.

[34] a) T. Shinagawa, A. T. Garcia-Esparza, K. Takanabe, Sci. Rep. 2015, 5 , 13801; b) J. Ma, A. Habrioux, Y. Luo, G. Ramos-Sanchez, L. Calvillo, G. Granozzi, P. B. Balbuena, N. Alonso-Vante, J. Mater. Chem. A 2015, 3, 11891-11904.

[35] Q. Li, D. Spernjak, P. Zelenay, Y. S. Kim, J. Power Sources 2014, 271, 561-569.

[36] a) E. Bayram, G. Yilmaz, S. Mukerjee, Appl. Catal., B 2016, 192, 26-34 b) W. Song, Z. Chen, C. Yang, Z. Yang, J. Tai, Y. Nan, H. Lu, J. Mater. Chem. A 2015, 3, 1049-1057; c) J. Xiao, Y. Xu, Y. Xia, J. Xi, S. Wang Nano Energy 2016, 24, 121-129; d) C. Lo Vecchio, D. Sebastián, C. Alegre, A. S. Aricò, V. Baglio, J. Electroanal. Chem. 2017.

[37] a) M. K. Jeon, P. J. McGinn, J. Power Sources 2010, 195, 2664-2668; b) F.-S. Zheng, S.-H. Liu, C.-W. Kuo, Int. J. Hydrogen Energy 2016, 41, 2487-2497. 


\section{Entry for the Table of Contents}

\section{ARTICLE}

Effective and scalable continuous flow route for the synthesis of PtNPs embedded in carbon porous spheres. Yields ORR catalysts for fuel cells with low Pt content, high duraility and high methanol-tolerance.

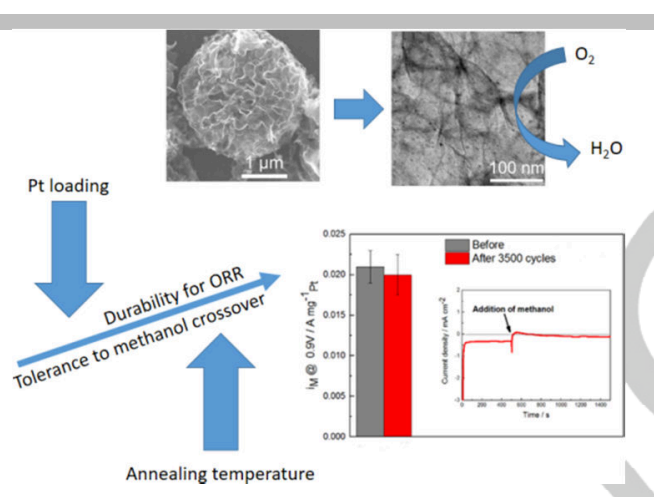

Carlota Domínguez, Kevin M. Metz, Md. Khairul Hoque, Michelle P. Browne, Leticia Esteban-Tejeda, Corbin K. Livingston, Suoyuan Lian, Tatiana S. Perova, Paula E. Colavita *

Page No. - Page No.

Continuous flow synthesis of Pt nanoparticles in porous carbon as durable and methanol-tolerant electrocatalysts for oxygen reduction reaction 